\title{
tinman and bagpipe: two homeo box genes that determine cell fates in the dorsal mesoderm of Drosophila
}

\author{
Natalia Azpiazu and Manfred Frasch \\ Brookdale Center for Molecular Biology, Mount Sinai School of Medicine, New York, New York 10029 USA
}

\begin{abstract}
Whereas the mechanisms of early Drosophila mesoderm formation have been studied in much detail, the subsequent processes determining regional identities within the mesoderm remain largely unknown. Here, we describe two homeo box genes, tinman (tin) and bagpipe (bap), which spatially subdivide the mesoderm and determine cell fates in the dorsal mesoderm. These two genes are components of a cascade of genetic interactions that result in the spatial restriction of tin mRNA to the dorsal mesoderm and in the activation of bap in segmental clusters of cells in this region. A subset of cells from those clusters segregate to form visceral mesoderm that differentiates into gut musculature. This indicates that the visceral mesoderm is derived from metamerically repeated primordia. In embryos mutant for bap, visceral mesoderm formation is strongly disrupted. Most cells of the visceral mesoderm fail to differentiate properly, and a portion of them are transformed into body wall musculature and gonadal mesoderm. In tin mutant embryos, bap expression is not activated in the dorsal mesoderm. Probably as a consequence, neither visceral mesoderm nor midgut musculature are formed in these mutants, and the absence of visceral mesoderm results in strong disruptions of endoderm migration and midgut morphogenesis. In addition to visceral mesoderm development, tin is required for the formation of the heart from dorsal mesoderm and for the specification of founder cells for particular body wall muscles.
\end{abstract}

[Key Words: Drosophila dorsal mesoderm; homeo box genes; tinman; bagpipe; cell fate]

Received April 1, 1993; revised version accepted May 17, 1993.

Recently, the mechanisms of mesoderm formation have been under intense study both in Drosophila and in vertebrate systems. In amphibian embryos, the mesoderm is formed by inductive processes, and mesoderm induction appears to be intimately coupled with the regional subdivision of the mesoderm into dorsal and ventral primordia (for review, see Smith 1989; Ruiz i Altaba and Melton 1990; Kimelman et al. 1992). It has been proposed that, prior to gastrulation, the organizing region of the dorsal mesoderm becomes subdivided into several smaller centers, and the differential spatial expression of several genes encoding potential transcription factors in this region may reflect these subdivisions (Gerhart et al. 1991; von Dassow et al. 1993). Further regionalization of the mesoderm occurs during gastrulation and is triggered by the dorsal mesoderm, leading to the determination of individual cell fates along the dorso/anterior to ventro/ posterior embryo axis. However, the mechanisms of this chain of inductive processes appear to be complex and are so far only poorly understood.

As a result of extensive genetic studies, a rather clear picture has emerged of the early events of Drosophila mesoderm formation which, in contrast to Xenopus, are regulated in a cell autonomous fashion. The nuclear gradient of the maternally expressed morphogen dorsal de- termines the expression domains of the zygotic genes twist and snail in the ventral-most region of the early embryo (Roth et al. 1989; Rushlow et al. 1989; Steward 1989; Jiang et al. 1991; Thisse et al. 1991; Ip et al. 1992). During gastrulation, this region of the embryo invaginates to form the mesoderm. The gene products of these two genes are likely to act as transcription factors, and the activities of both of them are required for mesoderm formation (Simpson 1983; Boulay et al. 1987; Thisse et al. 1988). It seems that the primary function of snail is to repress several nonmesodermal genes in the mesoderm primordium. twist, on the other hand, is thought to play a key role in activating a number of downstream genes that function in the process of invagination and mesoderm differentiation (Kosman et al. 1991; Leptin 1991). At present, few candidates for twist target genes are known.

In contrast to the early events of Drosophila mesoderm formation, we have much less information about the subsequent steps of the regional subdivision into the primordia of individual mesodermal tissues. Unlike vertebrate embryos, in Drosophila most of the events of mesoderm regionalization seem to occur after the completion of gastrulation, when the mesoderm has spread to form a layer of cells on the inside of the ectoderm. 
During and shortly after gastrulation, individual mesodermal cells do not appear to be committed to particular developmental fates (Beer et al. 1987). A major, and perhaps one of the earliest, decisions for differential development leads to the subdivision of the mesoderm into the visceral primordia and the somatic primordia. The visceral mesoderm gives rise to gut musculature, whereas the somatic mesoderm develops into the body wall musculature. Morphologically, these two primordia are first distinguishable about $3 \mathrm{hr}$ after the onset of gastrulation. At this stage, the visceral mesoderm /splanchnopleura) forms a separate layer located dorsally and interiorly, whereas the somatic mesoderm layer (somatopleura) contacts the ectoderm and neuronal cells and extends to the ventral midline (Poulson 1950). Somewhat later, founder cells for individual body wall muscles become specified in the somatic mesoderm in a process that involves the neurogenic genes (Bate 1990; Dohrmann et al. 1990; Corbin et al. 1991). The fat body is formed from cells of the ventrolateral mesoderm, and cells at the dorsal crest of the mesoderm are specified to develop into the heart (Poulson 1950; Hartenstein and Jan 1992).

Here, we describe two homeo box genes that function in the early phase of the regional subdivision of the mesoderm. The tinman (tin) gene (msh-2) was shown previously to be activated downstream of twist, and its expression becomes restricted to the dorsal mesoderm (Bodmer et al. 1990). Genetic analysis shows that tin function is required for the formation of visceral musculature, the heart, and the normal development of body wall muscles from the dorsal mesoderm. A second homeo box gene, bagpipe (bap), is also expressed in the dorsal mesoderm but only in segmental clusters of cells, and its expression depends on tin. The visceral mesoderm was found to form from segmental primordia in the dorsal mesoderm, which correspond to a subset of the bap-expressing cells. In bap mutant embryos the majority of these cells fail to become specified as visceral mesoderm.

\section{Results}

\section{The homeo box genes tin and bap map close} to each other

The two homeo box genes tin and bap were contained in a genomic walk that was initiated from the S59 homeo box gene (Dohrmann et al. 1990) and map the 93E1. The homeo box sequences of tin (NK-4) and bap (NK-3) were first determined by Kim and Nirenberg (1989). Using genomic DNA fragments containing the homeo box regions, we isolated cDNAs for the two genes. The longest tin cDNAs were $1.75 \mathrm{~kb}$, and the sequence of a cDNA of similar length has been reported previously (Bodmer et al. 1990). The longest bap cDNAs were $1.5 \mathrm{~kb}$ in length. The sequence of a bap cDNA is shown in Figure 1A and contains a long open reading frame coding for 382 amino acids. The homeo domain is located in the middle region of the polypeptide. Its sequence is $59 \%$ identical to the tin homeo domain (Kim and Nirenberg 1989). This homeo domain is most similar to a family of homeo domains, including those of the Drosophila genes tin and NK-2 (Kim and Nirenberg 1989), the human gene H6 (Stadler et al. 1992), the rat gene TTF-1 (Guazzi et al. 1990), and the mouse genes Nkx-2.2, Nkx-2.3, and Nkx2.4 (Price et al. 1992). Several of these genes also share a short sequence motif carboxy-terminal to the homeo domain, which is present in bap in a more degenerate form (Fig. 1A; Price et al. 1992).

Southern analysis with cDNA probes indicates that the genes do not contain large introns, and each of the cDNAs is encoded within $2.5-3 \mathrm{~kb}$ of genomic sequences. The two genes map close together and are transcribed in the same direction (see Materials and methods). With the assumption that our cDNAs are close to full length (see Fig. 2) and that there are no miniexons, the transcription start site of bap would be $6.5 \mathrm{~kb}$ downstream of the $3^{\prime}$ end of the tin gene (Fig. 1B).

\section{Sequential appearance of tin and bap expression in the dorsal mesoderm}

In Northern analysis of poly $(\mathrm{A})^{+}$RNA from different developmental stages, we detect a 1.8-kb mRNA for tin and a 1.55-kb mRNA for bap (Fig. 2). tin mRNA is first expressed between 2 and $4 \mathrm{hr}$ and reaches peak levels between 4 and $8 \mathrm{hr}$ after fertilization. In late embryonic stages, tin expression decreases dramatically, and no expression is observed in postembryonic stages. bap expression starts shortly after that of tin, between 4 and 8 hr of development. There is a slight decrease of bap mRNA levels between 8 and $12 \mathrm{hr}$ of development and a strong decrease in subsequent stages. (Fig. 2).

We analyzed the spatial patterns of tin and bap expression by in situ analysis of whole mounts and cross sections of embryos using tin or bap cDNA inserts as hy-

Figure 1. Molecular and genetic characterization of the genes tin and bap. (A) Nucleotide and deduced amino acid sequence of bap cDNA clone 4. The sequence of the homeo domain is boxed. Amino acids shared with other members of the NK homeo box gene family are shaded. The heptanucleotide that matches the consensus sequence for translation start sites (Cavener 1987) is boxed, and a consensus sequence for polyadenylation is underlined. $(B)$ Molecular structure of the tin/bap locus in wild type and mutants. The solid line depicts a restriction map of a $24-\mathrm{kb}$ region containing the genes tin and bap. Abbreviations: $(\mathrm{B})$ BamHI; (R) EcoRI; (S) SalI. (Above) The genomic regions used for P-rescue of tin mutants (CasPerRe28) and bap mutants (CasPerRe3). (Below) The transcription units of the two genes (see Materials and methods). (Bottom) The molecular structure of mutants in the region. $\mathrm{P}\left(w^{+} \mid 142\right.$ is a transposable element inserted upstream of $\operatorname{tin} \operatorname{tin}^{346}$ is a small EMS-induced deletion. The solid region indicates its length $(\sim 130 \mathrm{bp})$; vertical lines show its possible location. $P 142 \Delta 15$ and $P 142 \Delta 32$ are deletions obtained in an excision screen of the transposable element $\mathrm{P}\left(w^{+}\right) 142$. The distal breakpoint of the larger deletion $D f(3 R) G C 14$ maps between tin and bap (shaded region). 
Downloaded from genesdev.cshlp.org on April 26, 2023 - Published by Cold Spring Harbor Laboratory Press

Cell fate determination in dorsal mesoderm
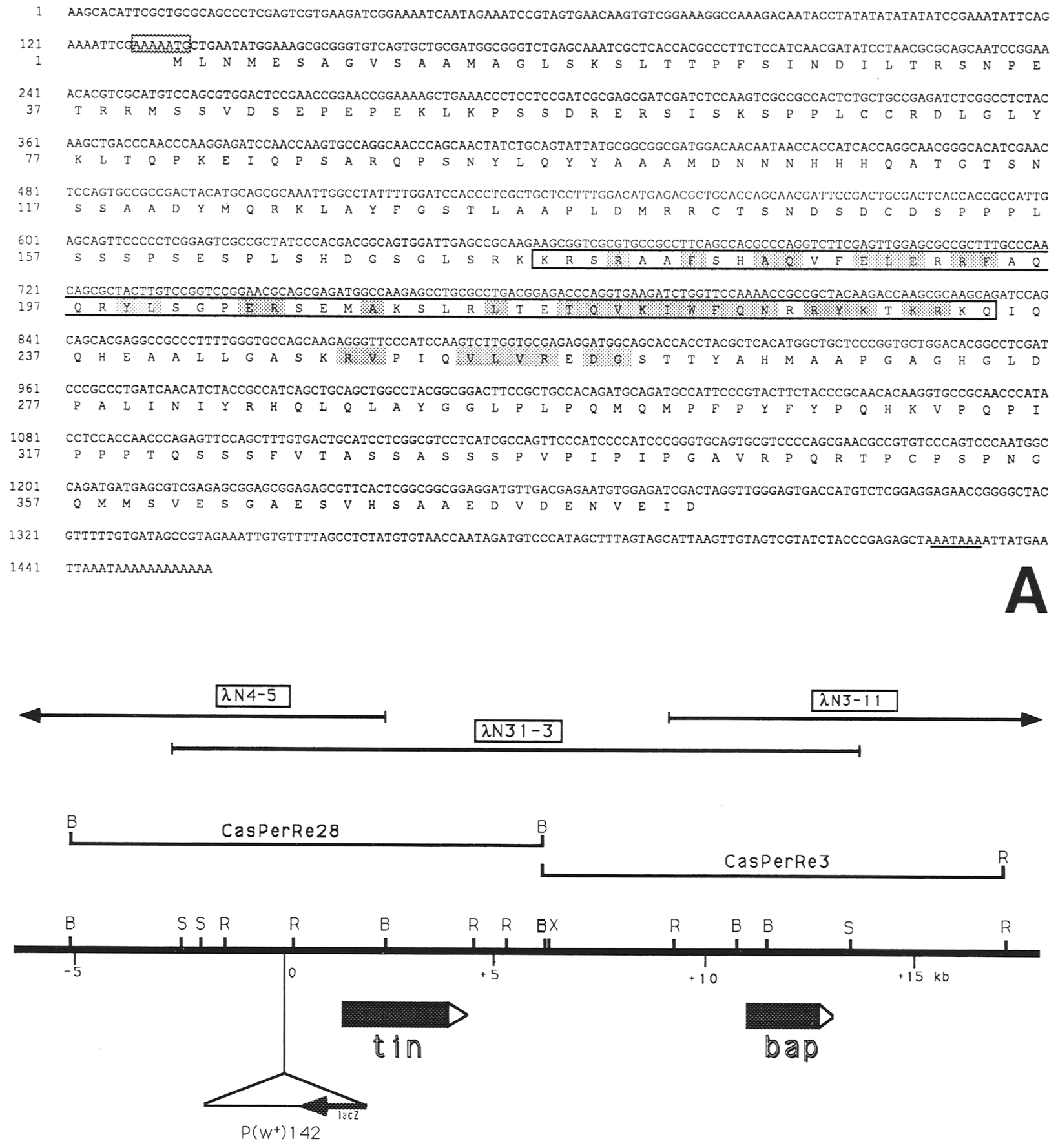

|||||||||||||| $\operatorname{tin} 346$

Figure 1. (See facing page for legend.) 


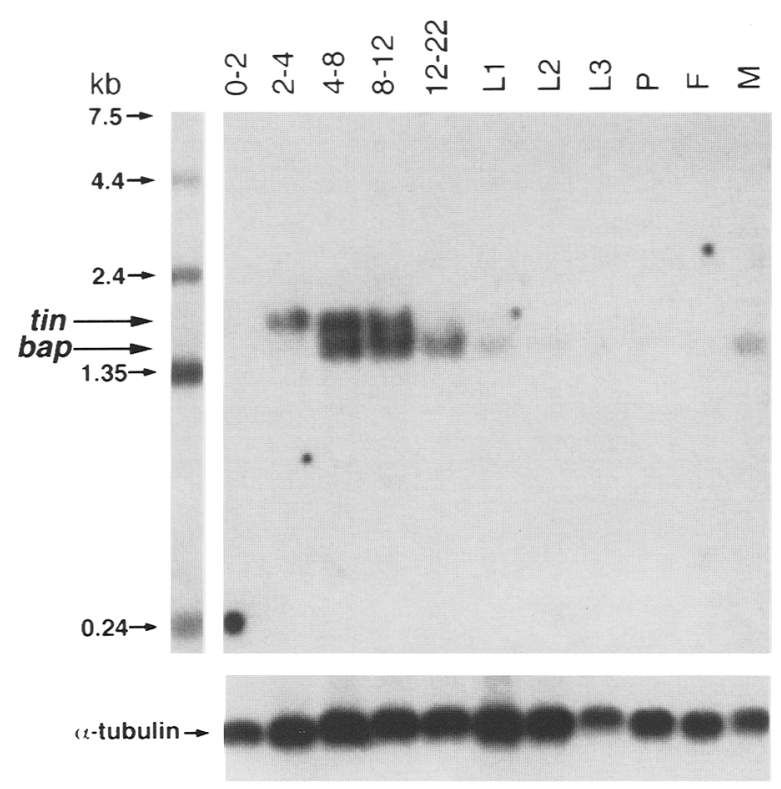

Figure 2. Northern analysis of tin and bap mRNAs. Poly $|\mathrm{A}|^{+}$ RNA from 0 - to $2-\mathrm{hr}, 2$ - to $4-\mathrm{hr}, 4-$ to $8-\mathrm{hr}, 8-$ to $12-\mathrm{hr}$, and 12to 24-hr embryos, from first (L1)-, second (L2)-, and third (L3)instar larvae, from pupae $(P \mid$ and from adult females $\langle F\rangle$ and males $(M)$ was tested. The blot was sequentially hybridized with the two probes, exposed for $60 \mathrm{hr}$ each time, and photograph from a sandwich of the two X-ray films. A relative amounts of poly $(\mathrm{A})^{+}$RNA in each lane were estimated by hybridization with an $\alpha$-tubulin probe.

bridization probes. Initial expression of tin mRNA occurs in late cellular blastoderm in the ventral-most region of the embryo that corresponds to the cells containing high levels of twist protein (Figs. 3A and 10A). After invagination of the ventral cells into the interior of the embryo, tin mRNA is seen exclusively in mesodermal cells (Fig. 3B). All mesodermal cells in each section contain the same level of tin mRNA at this time. During stage 9 of development, after formation of a mesodermal monolayer under the ectoderm, cells in the ventral and lateral parts of the mesoderm display reduced levels of tin mRNA (Fig. 3C); and by stage 10, tin expression has become completely restricted to six to eight cells on either side in the dorsal-most regions of the mesoderm (Fig. 3D). During stage 11, after the third round of mitotic divisions in the mesoderm, each tin-expressing region splits into two separate domains (Fig. 3E, arrows): The first domain corresponds to visceral mesodermal cells that form a distinct layer in the dorsal-interior region, adjacent to the yolk sac. tin is expressed only transiently in these cells of the splanchnopleura, and expression ceases in late stage 11 . The second domain consists of a few cells at the dorsal tip of the mesoderm, adjacent to the ectoderm. These cells include the precursor cells of the heart. tin continues to be expressed in heart progenitors until late stages of embryogenesis when they differentiate into the dorsal blood vessel (Fig. 4C; see also Bodmer et al. 1990). bap starts to be expressed at stage 10 , after the restriction of tin mRNA to the dorsal mesoderm. From its onset, bap expression is limited to the dorsal-most cells of the mesoderm. In contrast to tin expression in the dorsal mesoderm, which at stage 10 is continuous along the anterior-posterior axis, bap expression is segmentally interrupted (Fig. 4, cf. A with B). The 11 patches of bap expression are located in the region corresponding to parasegments $2-12$ of the epidermis. This region of the mesoderm will give rise to the visceral mesoderm of the midgut (Tremml and Bienz 1989a). Double stainings for bap mRNA and engrailed protein reveal accurate alignment between the anterior borders of the bap patches and the parasegmental borders of the epidermis (Fig. 10B). bap expression in the dorsal mesoderm is transient and disappears during stage $11, \sim 21 / 2 \mathrm{hr}$ after its onset. In addition to the middle body region, bap is expressed in mesodermal cells at the proctodeum and stomodeum.

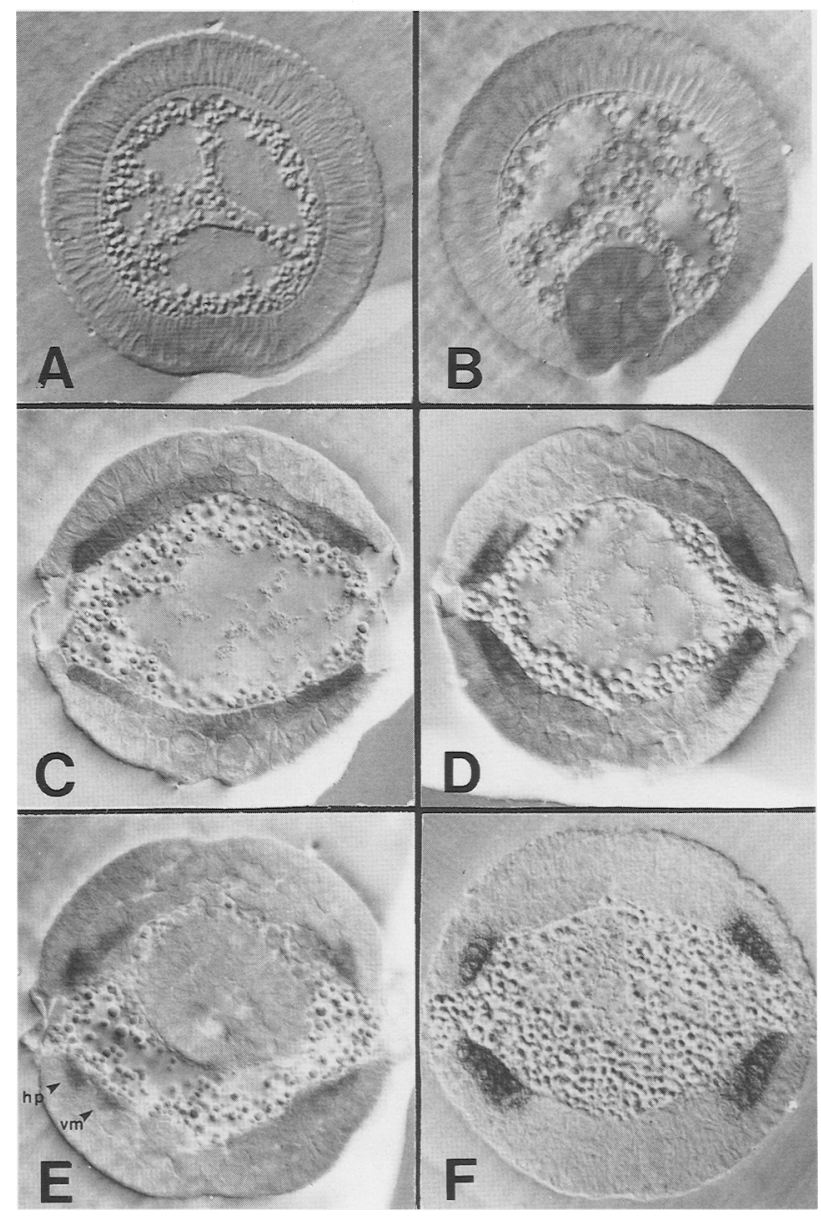

Figure 3. Expression of tin and bap mRNAs in early embryonic development. Embryos were hybridized with tin $(A-E)$ or bap $(F)$ probes and sectioned. Shown is an embryo at the beginning $(A)$ and after $(B)$ gastrulation. All mesodermal cells express tin. Between stage $9(C)$ and stage $10(D)$, tin mRNA becomes restricted to dorsal mesodermal cells. (E) Stage 11. tin expression in visceral mesoderm cells (vm) and heart precursors (hp). $(F)$ Stage 10. bap mRNA appears in the dorsal mesoderm. 


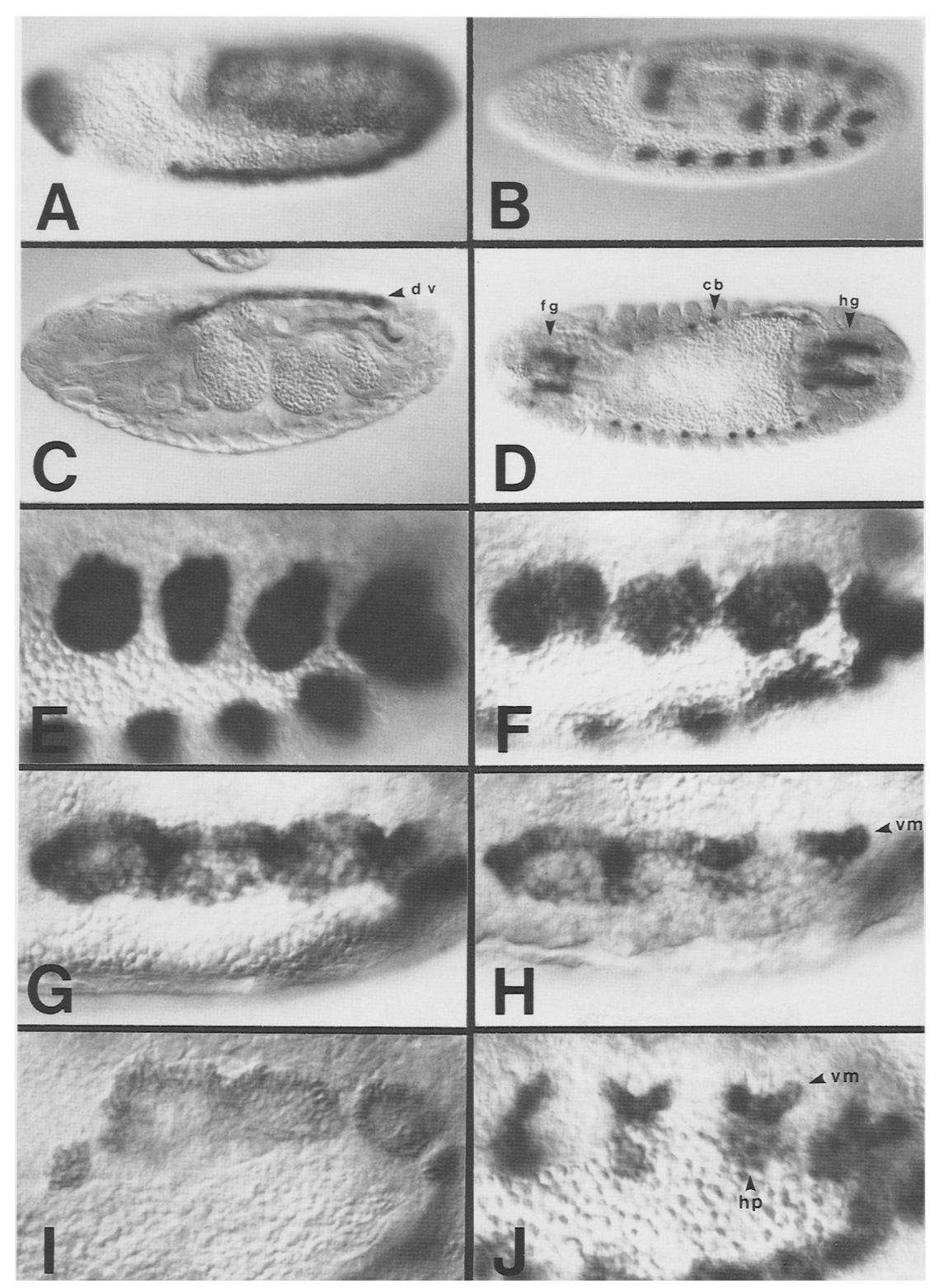

Figure 4. tin and bap expression in whole embryos and morphogenesis of the visceral mesoderm. $(A)$ tin mRNA distribution (stage as in Fig. 3C) with reduced expression in the ventral mesoderm and ectodermal expression at the anterior pole. (B) bap expression (stage as in Fig. 2F) in 11 patches in the dorsal mesoderm and in the proctodeal mesoderm. (C) Stage 16. tin expression in the heart [dorsal vessel (dv)]. (D) Stage 15; bap expression in the musculature of foregut $(\mathrm{fg})$ and hindgut $(\mathrm{hg})$ and in cardioblasts (cb). (E) bap mRNA expression at stage 10 ; high magnification view. $(F)$ Early stage 11 . $(G)$ Mid-stage 11 . (H) Later stage 11 . The bap patches begin to merge and cells of the visceral mesoderm (vm) segregate. (I) Mid-stage 11; embryo stained with fasciclin III antibodies. (J) Late stage 11. tin expression in portions of the visceral mesoderm (vm) and in dorsal cells that include heart progenitors (hp).
These cells will develop into the visceral mesoderm of the hindgut and foregut, and they continue bap expression until late embryogenesis (Fig. 4D). Following stage 12 , bap expression appears in a subset of heart progenitors (Fig. 4D).

Using bap as a marker we were able to study the developmental processes that lead to the segregation of the visceral and the somatic mesoderm from undifferentiated dorsal mesodermal cells. Initially, bap is expressed in patches that consist of an average of $\sim 17$ cells each (Fig. 4E). In early stage 11, during and after a mitotic division, the cells of the bap patches rearrange such that the patches elongate along the anterior/posterior embryo axis and finally merge with each other (Fig. 4F,G). Shortly before the patches merge we observe that the bap-expressing cells split into two morphologically dis- tinct populations. The cells at the ventral periphery of each patch assume a columnar shape, whereas those in the central and dorsal parts of the patches remain hexagonal. Eventually, the rows of columnar cells from each patch connect with each other and form the continuous band of the visceral mesoderm (Fig. 4G,H). bap expression strongly declines during this process, persisting somewhat longer in the visceral mesoderm cells of the regions where the patches have merged (Fig. 4H). From these observations we conclude that the visceral mesoderm forms from segmentally arranged primordia in the dorsal mesoderm. However, because of a lack of a marker, we cannot completely rule out that some cells from the bap interstripe regions contribute to the visceral mesoderm as well. Only $30-40 \%$ of the bap-expressing cells develop into visceral mesoderm, and we 
assume that the remaining cells from each patch give rise to somatic mesoderm.

Some of these aspects of visceral mesoderm formation can also be analyzed using the cell-surface protein fasciclin III (Snow et al. 1989) and tin as markers. At its onset in stage 11 , fasciclin III is expressed in patches similar to those of bap, and strong expression occurs in the cells at the ventral periphery of these patches (Fig. 4I). These cells subsequently form the band of visceral mesoderm cells that continue to express fasciclin III until stage 13 (see below). In late stage 11 , residual tin-expression is seen in those cells of the visceral mesoderm in which bap persists longest as well (Fig. 4, cf. J with $\mathrm{H}$; for a cross section, see Fig. 3E).

In summary, the main area of tin and bap expression is the dorsal mesoderm. At the time when tin becomes restricted to this region, bap expression is activated in segmental subsets of these dorsal mesodermal cells. Subsequently, the cells located at the ventral periphery of the bap patches segregate and merge to form the visceral mesoderm.

\section{tin and bap have essential functions}

To study the functions of tin and bap, we produced mutations in the two genes. By genomic Southern analysis we found that a small deficiency, $D f(3 R) G C 14$ (Mohler and Pardue 1984), has its distal breakpoint in a $3 \mathrm{~kb}$ $X b a I-E c o R I$ fragment in between the two genes and deletes tin (Fig. 1B). A large deficiency, $D f(3 R) e^{D 7}$, deletes the chromosomal region between $93 \mathrm{C}$ and $93 \mathrm{~F}$, which includes the region where both genes map (Scalenghe and Ritossa 1977; Mohler and Pardue 1984). Males carrying marked wild-type chromosomes were treated with ethylmethane sulfonate (EMS), and the mutagenized chromosomes were screened for mutations that were lethal in trans to $D f(3 R) e^{D^{7}}$. (see Materials and methods). Eighty-five mutants were recovered in this saturation screen.

Two complementation groups mapped within the smaller deficiency, $D f(3 R) G C 14$, and one of them, with a total of five mutant alleles, corresponded to the tin gene. Genomic Southern analysis revealed that the $\operatorname{tin}^{346}$ chromosome contains a small deletion of $\sim 130 \mathrm{bp}$ within the tin transcription unit (Fig. 1B). The $\operatorname{tin}^{346}$ mutation confers embryonic lethality. $\operatorname{tin}^{346}$ appears to be a null allele, because the mesodermal phenotype caused by this mutation is identical to that caused by the deficiency $D f(3 R) G C 14$. A second allele, $t^{45}$, shows an almost complete null phenotype, whereas $\operatorname{tin}^{212}$, $\operatorname{tin}^{294}$, and $t^{305}$ exhibit less severe phenotypes in homozygous embryos (see below).

Another complementation group with a single allele mapped between the distal breakpoints of $D f(3 R) G C 14$ and $D f(3 R) e^{F 1}$ (Mohler and Pardue 1984), where bap is located. Animals homozygous for this mutation or in combination with a deficiency die as first-instar larvae. To demonstrate that this mutation corresponded to a mutation in the bap gene and that the complementation group described above corresponded to tin, we tried to rescue the mutant phenotypes by P-element transformation with wild-type genomic sequences. An 11-kb fragment from the bap region carried in a P-element vector (CasPerRe3, Fig. 1B) rescued the lethality of $b a p^{208}$ / $D f(3 R) e^{D 7}$. Because Northern and in situ hybridizations did not detect expression of any genes other than bap from this $11-\mathrm{kb}$ region, this result strongly suggests that the mutation maps in the bap homeo box gene itself. Similarly, a 10.7-kb genomic fragment covering the tin transcription unit (CasPerRe28, Fig. 1B) rescued the lethality of strong tin mutations $\left[\operatorname{tin}^{346} / D f(3 R) e^{D 7}\right]$, confirming the identity of this complementation group with the tin gene.

We also screened for P-element insertions in the genomic region of tin and bap to recover mutations in the two genes (see Materials and methods) and identified an insertion located $\sim 1.3 \mathrm{~kb}$ upstream of the presumed transcription start site of tin (Fig. 1B). The insertion caused only a very mild embryonic phenotype, and flies with the insertion in trans to a deficiency are viable. However, imprecise excision of this element with P-transposase allowed the isolation of several small deletions. These deletion alleles are lethal in trans to EMS alleles of tin. By Southern analysis, two of these deletions, $\Delta 15$ and $\Delta 32$, were mapped to upstream regions of the tin gene (Fig. 1B).

\section{tin and bap are required for the specification of the visceral mesoderm}

The expression patterns of tin and bap suggested a function of these homeo box genes in the visceral mesoderm development. In wild-type embryos of stage 12 , the visceral mesoderm of the future midgut forms a continuous band of cells along the germ band that contacts the yolk sac. This splanchnopleura has by then separated from the somatopleura and expresses fasciclin III (Fig. 5A). After germ-band retraction, the band of the visceral mesoderm broadens as the cells assume a palisade-like shape and interdigitate (Fig 5B; Campos-Ortega and Hartenstein 1985). In later stages, each band splits into two, and the cells migrate and spread around the midgut endoderm to form the gut musculature (Fig. 5C; Reuter and Scott 1990; Hartenstein and Jan 1992).

In stage 12 embryos mutant for strong alleles of tin, no fasciclin III can be detected in the mesoderm, whereas the ectodermal and neuronal expression is normal (Fig. 5D). Similarly, after germ-band retraction, the columnar cells of the visceral mesoderm can neither be detected by fasciclin III staining nor by morphological examination (Fig. 5E). In late-stage embryos, the midgut musculature is completely missing, as shown with an enhancer trap insertion that normally expresses $\beta$-galactosidase ( $\beta$-gal) in the visceral mesoderm of the midgut (Fig. 5C,F; Bellen et al. 1989). These results show that the visceral mesoderm of the midgut region is never formed in embryos homozygous for null mutations of $t i n$. In embryos mutant for weak alleles, the band of the visceral mesoderm is interrupted by gaps of variable width (results not shown|. In null mutants, the yolk sac does not form any 


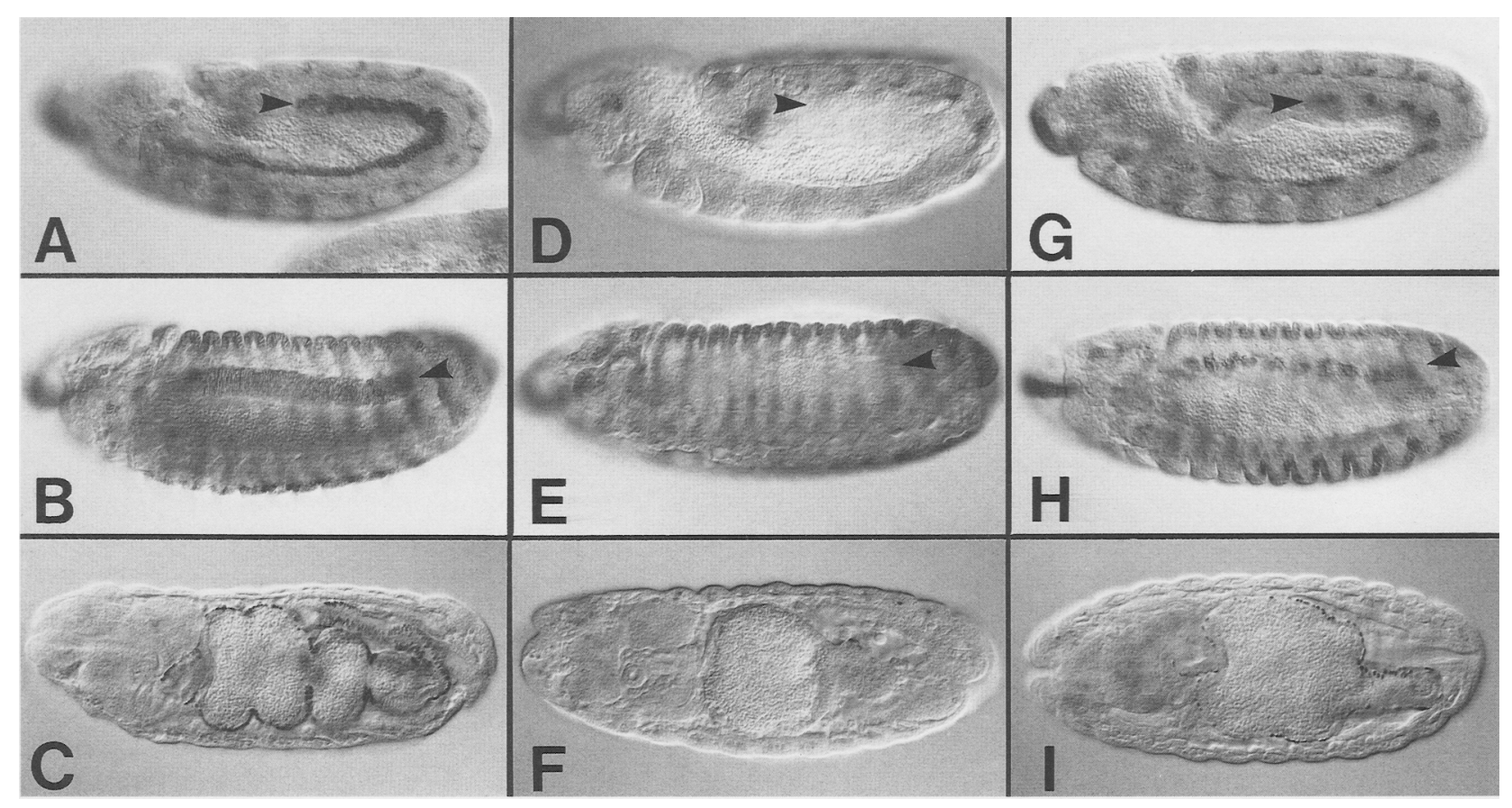

Figure 5. Functions of tin and bap for visceral mesoderm development. $(A-C)$ Wild-type; $(D-F)$ tin mutants; $(G-I)$ bap mutants. Shown are stage $12(A)$, and stage $13(B)$ wild-type embryos stained for fasciclin III protein. Arrowheads indicate visceral mesoderm. Additional expression occurs in the epidermis. (C) Stage 16 wild-type embryo with the enhancer trap insertion A176, stained with $\beta$-gal antibodies. The nuclei of the midgut musculature are stained. They form four equidistant lines along the midgut. Three midgut constrictions are seen. Shown are stage $12(D)$, and stage $13(E)$ tin mutant embryos stained as in $A$. The visceral mesoderm of the midgut region is absent. $(F)$ Stage 16 tin mutant embryo containing the Al76 insertion, stained as in $C$. The midgut visceral mesoderm is missing, except for a few cells in the posterior part, and no midgut constrictions are formed. Shown are stage 12 (G), and stage 13 (H) bap mutant embryos stained as in $A$. The visceral mesoderm (arrowheads) is segmentally internupted, and the residual cells are irregular. $(I)$ Stage 16 bap mutant embryo containing the Al76 insertion, stained as in $C$. The number of visceral mesoderm cells is strongly reduced and the midgut lacks constrictions.

constrictions and remains globular or pear-shaped (Fig. $5 \mathrm{~F}$; see below). In contrast to the midgut, the foregut, proventriculus, and hindgut appear normal (Figs. 5F, 7B, $8 \mathrm{E}$, and $9 \mathrm{D})$.

In embryos mutant for bap, the band of the visceral mesoderm displays segmental interruptions from the earliest stages (i.e., late-stage 11) onward until germband retraction (Fig. 5G,H). As judged from the nuclear staining of the above-mentioned enhancer trap line, the number of visceral mesoderm cells is reduced by $\sim 70 \%$, as compared with wild-type embryos. The remaining cells have irregular shapes and are not columnar (Fig. $5 \mathrm{H})$. The late migration of the residual gut muscle cells occurs similarly as in wild type. However, the midgut fails to undergo any constrictions, and only the posterior part becomes narrower (Fig. 5I). Even though bap is also expressed in the foregut and hindgut mesoderm, we were unable to detect any abnormalities in these tissues.

We studied the developmental fates of the cells normally destined to form visceral mesoderm in bap mutant embryos. For this purpose, we produced transgenic lines expressing $\beta$-gal under the control of bap upstream elements. In stage 11 wild-type embryos transformed with such a reporter construct (see Materials and methods), $\beta$-gal is expressed in segmental repeats of cells of the visceral mesoderm (Fig. 6A). This pattern reflects the late phase of endogeneous bap expression (Fig. $4 \mathrm{H}$ ). The long half-life of the $\beta$-gal protein allowed us to examine the fates of these cells during later stages of development. The segmental arrangement of these cells in the visceral mesoderm of wild-type embryos is maintained until stage 13, when they elongate and start surrounding the midgut endoderm (Fig. 6B). After the formation of midgut constrictions, the $\beta$-gal-containing cells form part of the gut musculature and, in wild-type embryos, none of them gives rise to somatic muscles (Fig. 6C). In bap mutant embryos, the majority of cells derived from $\beta$-gal-expressing cells surround the midgut endoderm as well (Fig. 6D). However, they display abnormal morphologies in that they fail to assume a palisade-like structure during stage 12 and are arranged irregularly. Importantly, a portion of the $\beta$-gal-expressing cells is found as components of somatic muscles in bap mutant embryos (Fig. $6 \mathrm{D})$. Most often, the muscles that contain $\beta$-gal are located in the lateral region of the body wall musculature, although their identity and number is variable. In some bap mutant embryos, $\beta$-gal-containing cells are also found in the gonadal mesoderm (Fig. 6D). Thus, bap mu- 


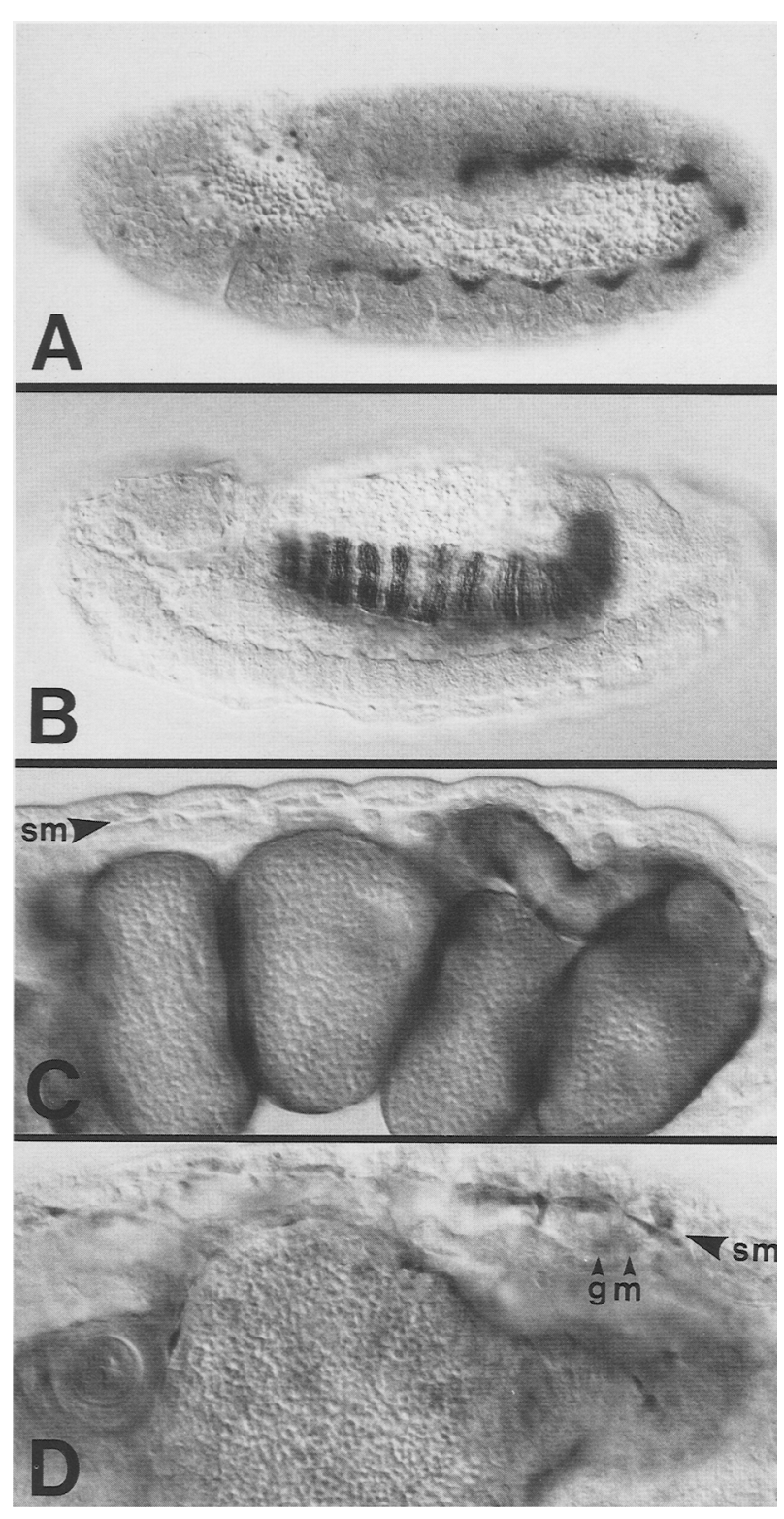

Figure 6. Transformation of cell fates in bap mutant embryos. lacZ expression from the promoter construct baplac4.5\#23 in wild-type and bap mutant backgrounds. $(A)$ Wild-type, stage 11 embryo hybridized with a digoxygenin-labeled $\beta$-gal probe. $\beta$-Gal mRNA is seen in segmental portions of the visceral mesoderm. Embryos in $B-D$ were stained with $\beta$-gal antibodies. $(B)$ Wild-type, stage 13 embryo. The progenitors of $\beta$-gal-expressing cells remain segmentally arranged in the visceral mesoderm. $(C)$ Wild-type, stage 16 embryo. The $\beta$-gal containing cells have formed visceral musculature. (D) bap mutant embryo, stage 16 . The $\beta$-gal stained cells around the midgut are abnormal, a number of cells have fused into syncitia of somatic muscles $(\mathrm{sm})$ and two $\beta$-gal cells are seen in the gonadal mesoderm (gm).

tation causes a transformation of a portion of cells from a visceral mesoderm fate to assume the identity of somatic or gonadal mesoderm. Because of the absence of $\beta$-gal expression from this construct in tin mutant em- bryos, we were unable to follow the fates of dorsal mesodermal cells in the absence of tin function.

\section{tin has a function in the development of body wall muscles}

The somatic mesoderm differentiates into the stereotypic pattern of the body wall muscles, which are arranged into ventral, pleural, and dorsal groups (Fig. 7A; Crossley 1978; Bate 1990). In tin mutant embryos, the pattern of body wall muscles is disrupted. Although some of these disruptions are a consequence of displacements by the voluminous yolk sac, we observe pattern abnormalities in other regions of the embryo as well. In particular, all muscles of the dorsal group appear enlarged and disorganized such that it is difficult to determine individual identities (Fig. 7B). Pattern disruptions are also observed in more ventral regions of the body wall musculature. For instance, muscles $4,5,6$ or 7 , and 25 are missing, and many other muscles are shaped and arranged abnormally (Fig. $7 \mathrm{C}$ ). Because the homeo box gene S59 is expressed in the founder cells of muscles 5 and 25 (and also in those of 18 and 27, which are present in $\operatorname{tin}^{-}$| we examined whether tin mutations affect the founder cell formation or later stages of muscle development. In late-stage 11, S59 labels the common founder cells of muscles 5 and 25 (I) and the founder cells of muscle 27 (II) (Fig. 7D; Dohrmann et al. 1990). In tin mutants of stage 11, only the founder cells of muscle 27 but not those of muscles 5 and 25 are detected (Fig. 7E). Correspondingly, in stage 12 tin mutant embryos, the muscle precursors 5 (Ia) and 25 (Ib) are undetectable with S59 antibodies (Fig. 7F,G). These results suggest that tin is involved in the formation of particular muscle founder cells. The absence of these founder cells in early mutant embryos results in the absence of the corresponding muscles later on. In $b a p^{-}$embryos, the body wall muscle pattern appears to be normal.

\section{Failure of endoderm migration in the absence of the visceral mesoderm}

The endoderm invaginates from both ends of the embryo to form the primordia of the anterior and posterior midgut. During stage 12, each of these primordia assumes a Y-shaped structure (Poulson 1950). The branches of these midgut primordia are associated with the bands of the visceral mesoderm on either side of the embryo and form the leading edges of the endoderm movement toward the center of the embryo (Fig. 8A). Both halves of the endoderm meet and fuse in late stage 12, before completion of germ-band retraction (Fig. 8B). Subsequently, the endoderm spreads toward the ventral and dorsal sides to surround the yolk sac. After formation of constrictions, the loops of the midgut and the gastric caecae are formed (Fig. 8C).

In tin mutants where the visceral mesoderm is absent, the midgut primordia lack the bilobate structures and do not appear to undergo active migration. Rather, the amorphous masses of the anterior and posterior endo- 


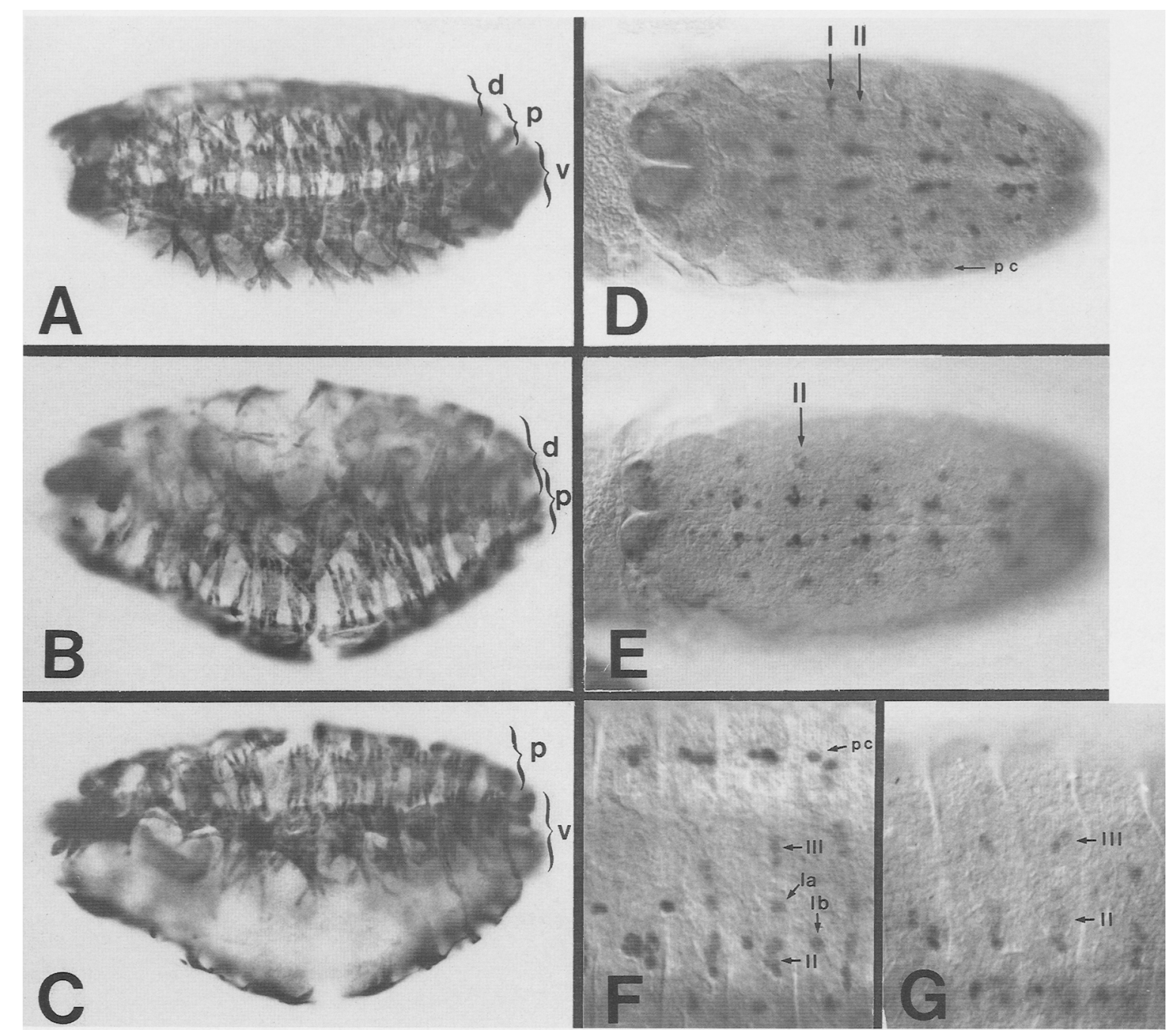

Figure 7. tin function for the formation of body wall muscles. $(A)$ Stage 17 wild-type embryo, stained for muscular myosin, lateral view. The segmentally repeated groups of ventral $(\mathbf{v})$, pleural $(\mathrm{p})$, and dorsal $(\mathrm{d})$ muscles are seen. Shown are a tin mutant embryo $(B)$, stained as in $A$, dorsolateral view; and same embryo $(C)$ ventrolateral view. The dorsal muscles are larger than in wild-type embryos and are arranged irregularly. The pleural and ventral muscles are relatively normal, although some are missing. $(D)$ Stage 11 wild-type embryo (posterior segments), stained for S59 and eve. S59 labels the founder cells of muscles 25 and 5 (I) and those of muscles 27 (II). There is also neuronal expression of both genes, and eve is seen in pericardial precursors (pc) and anal plate cells. (E) Stage 11 tin mutant embryo, stained as in $D$. The founder cells of muscles 25 and 5 (I) are absent, and only those of muscles 27 (II) are seen. $(F)$ Late stage 12 wild-type embryo, stained as in $D$, segments T3-A3. The precursors of muscles 25 (Ia), 5 (Ib), 27 (II), and 18 (III) are stained. (G) tin mutant embryo, stage and staining as in F. Muscle precursors 25 and 5 are absent, whereas those of muscles 27 (II) and 18 (III) are present. The number of muscle precursor cells in thoracic segments is reduced as well.

derm continue to be separated by yolk at stage 13 of development (Fig. 8D). This gap is only partially closed during the phase of lateral movements, when the endoderm surrounds the yolk sac. The density of endodermal cells remains low around the middle part of the yolk sac, and the majority of cells stay on either side of it (Fig. 8E). This observation suggests that in wild-type embryos the bands of the visceral mesoderm play an important role as a substrate along which the endoderm moves to form the midgut. This view is supported by the examination of the endoderm movements in bap mutants that display interrupted visceral mesoderm bands. In these embryos the migration of the endoderm is retarded and the anterior and posterior midgut meet about $1 \mathrm{hr}$ later than in wild type embryos (data not shown).

\section{tin is essential for heart formation}

Because the precursor cells of the heart are derived from the dorsal-most cells of the mesoderm and tin continues to be expressed in them throughout heart development, we examined whether the gene has a function in heart development. During heart formation, the precursor cells located on either side of the embryo meet along the 


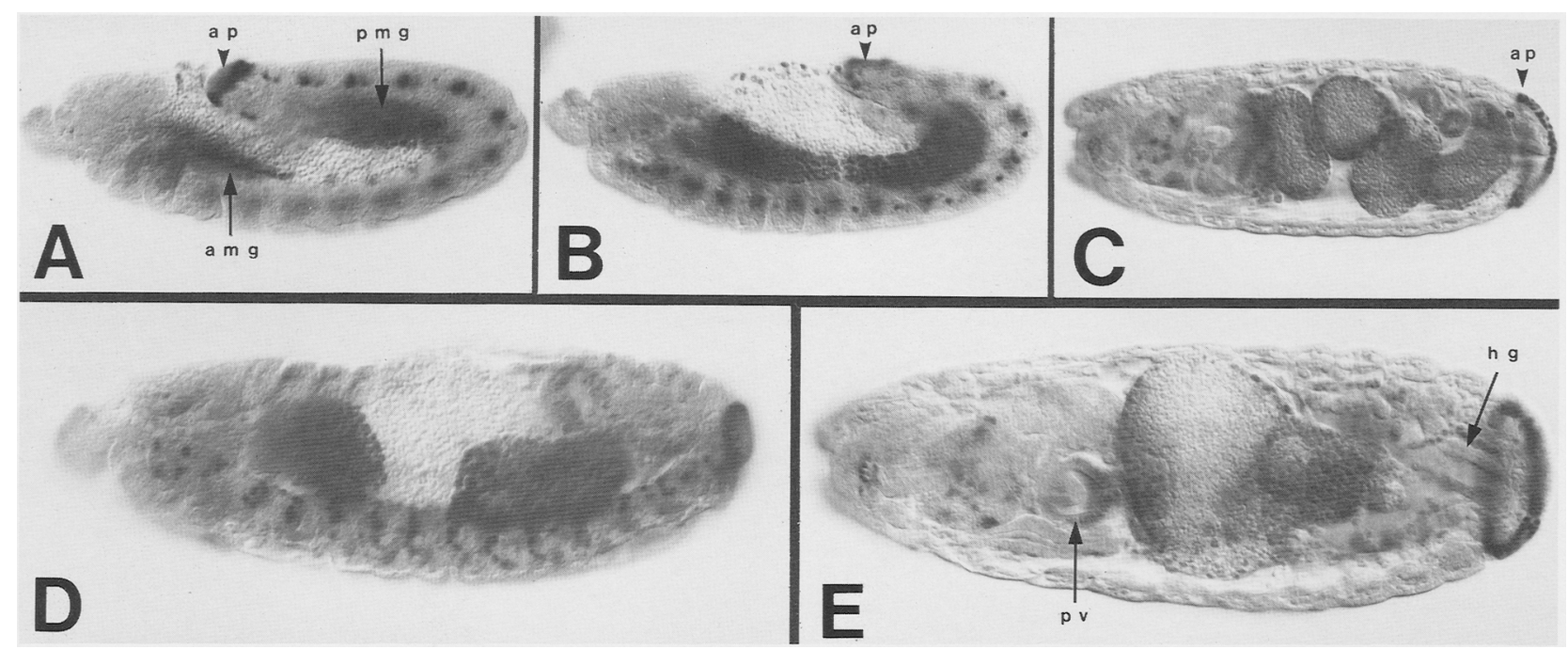

Figure 8. Disrupted endoderm migration in tin and bap mutants. The endoderm was visualized using the enhancer trap insertion A490. The embryos were additionally stained for eve to identify tin mutants. Anal plate staining (ap) marks the posterior end of the embryos. (A) Early stage 12 wild-type embryo. (amg) Anterior midgut; (pmg) posterior midgut. (B) Late-stage 12 wild-type embryo. Both halves of the endoderm have migrated toward each other and are about to fuse. $(C)$ Stage 16 wild-type embryo. Endoderm morphogenesis has proceeded to form several midgut loops. (D) Stage 13 tin mutant embryo. Anterior and posterior midgut endoderm remain separate. (E) Stage 16 tin mutant embryo. Most endoderm cells remain on either side of the yolk sac. (pv) Proventriculus; (hg) hindgut.

dorsal midline. The two rows of cardioblasts form a tube that is surrounded by the pericardial cells (Campos-Ortega and Hartenstein 1985; Hartenstein and Jan 1992) The homeo box gene even-skipped (eve) is expressed in segmental clusters of pericardial precursor cells from stage 11 onward (Fig. 9A; Frasch et al. 1987). This expression is absent in tin mutant embryos, suggesting that the precursors of the pericardial cells do not become specified (Fig. 9B). Fig. 9C shows a wild-type embryo after heart differentiation. The embryo carried an enhancer trap construct expressing $\beta$-gal in a subset of cardioblasts (stained brown), and pericardial cells were visualized by eve staining (purple). $\beta$-Gal is also expressed in the fat body and in the lymph glands. In a similarly stained tin mutant embryo carrying this enhancer trap insertion, both the cardioblasts and the pericardial cells were missing. None of the heart structures, with the exception of the lymph glands, were detectable (Fig. 9D). The same result was observed when tin mutant embryos were analyzed with other enhancer trap insertions expressing $\beta$-gal in the full complement of heart cells (results not shown). Thus, tin function is essential for the specification of the heart precursor cells. In contrast, bap mutant embryos form a normal heart (not shown). The fat body develops in both mutants, consistent with the observation that its precursors are derived from more ventral mesodermal regions (Fig. 9D; Hartenstein and Jan 1992).

bap expression is regulated by tin

bap starts to be expressed in dorsal mesodermal cells shortly after tin expression has become restricted to these regions. To test the possibility that the tin homeo domain protein is involved in activation of the bap gene, we examined bap RNA expression in tin mutant embryos. In strong tin mutants bap expression was almost abolished in the middle body region (Fig. 10C), and in embryos homozygous for weak alleles the bap patches were reduced in size and intensity (not shown). bap expression in the stomodeal and proctodeal mesoderm, which is outside the tin expression domain, was not affected (Fig. 10C). Therefore, in wild-type embryos, tin is required to activate bap expression in the region that includes the presumptive midgut visceral mesoderm. Because, at this stage, tin expression in the dorsal mesoderm is continuous along the anterior-posterior axis, whereas bap expression is striped, additional regulators must modulate bap expression in a segmental manner.

\section{Discussion}

The analysis of the expression patterns and functions of the two genes described in this study, tin and bap, provides us with novel insights into the mechanisms that lead to the differential specification of cell fates in the mesoderm. It appears that a cascade of gene interactions results in a progressively finer subdivision of the mesoderm that gives rise to the formation of individual mesodermal tissue types from these regions.

\section{Regulation of tin and bap expression}

tin is initially expressed in the whole mesoderm, probably being activated by the twist gene product (Fig. 10A; Bodmer et al. 1990). Subsequent processes refine its expression pattern such that tin becomes restricted to the 


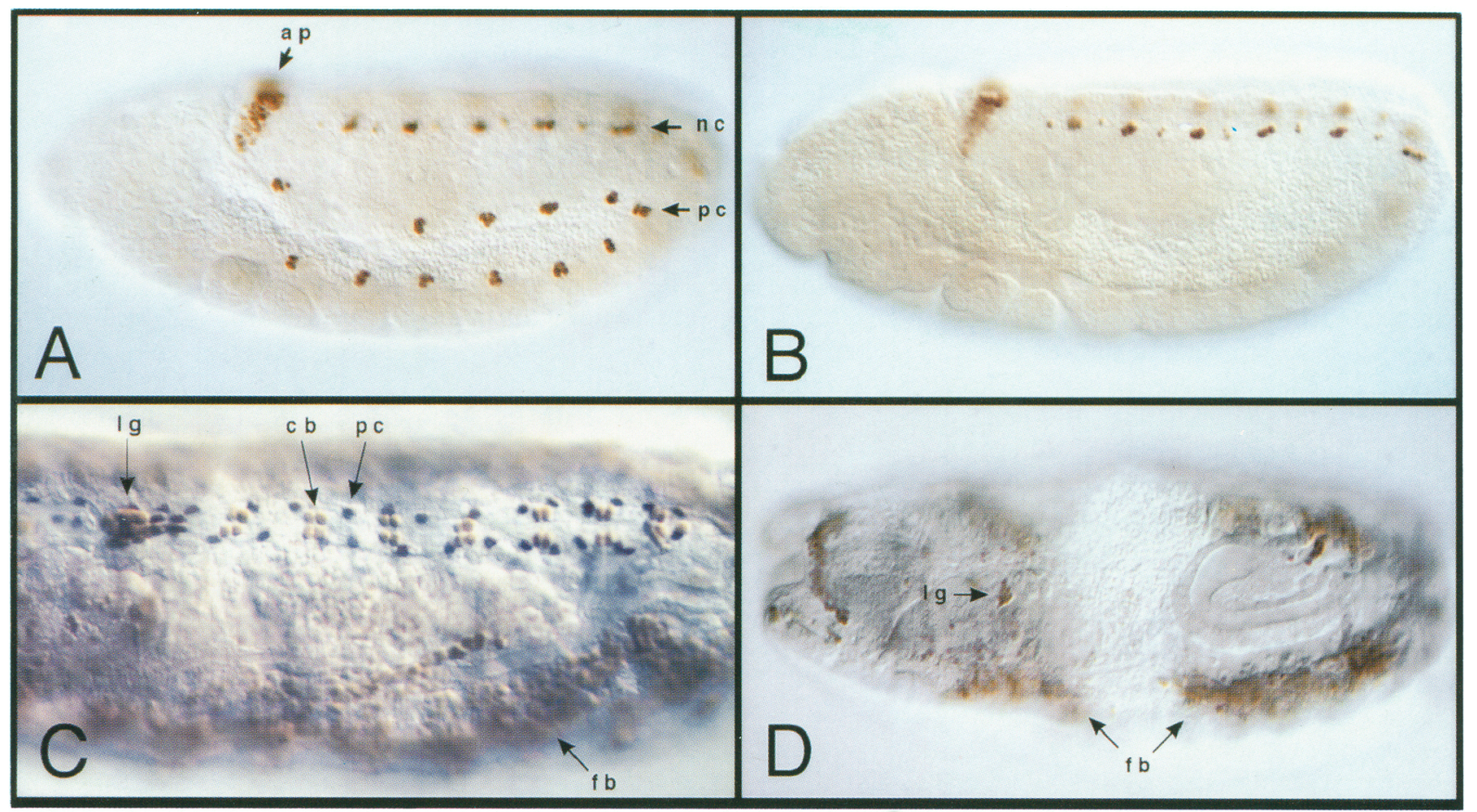

Figure 9. tin function for the formation of the heart. (A) Stage 11 wild-type embryo stained for eve. (pc) Precursors of pericardial cells; (nc) neuronal precursors of the CNS; (ap) cells at the presumptive anal plate. (B) Stage 11 tin mutant embryo, lacking eve staining of the pericardial precursor cells. $(C)$ Stage 17 wild-type embryo containing the enhancer trap insertion E2-3-9, double stained with antibodies against eve (purple) and $\beta$ gal (brown). The pericardial cells (pc) are located at the periphery of the dorsal vessel. $\beta \mathrm{Gal}$ labels segmental subsets of cardioblasts (cb), the lymph gland $(\mathrm{lg})$, and the fat body (fb). (D) Stage 17 tin mutant embryo with the E2-3-9 insertion, stained as in C. Neither cardioblasts nor pericardial cells are detected. The interruptions seen in the lobes of the fat body may be the result of displacements by the large yolk sac.

dorsal mesoderm. The dorsal restriction of tin expression is perhaps one of the earliest steps in the spatial subdivision of the mesoderm. At present, we do not have any information about the mechanisms involved in this restriction. The cells that will form the dorsal mesoderm could already be determined during blastoderm according to their position along the dorsoventral embryo axis as a result of the graded distribution of the dorsal morphogen. However, because of the topological rearrange- ments during the collapse of the invaginating mesodermal tube and during the subsequent spreading of mesodermal cells along the ectoderm, such a mechanism seems unlikely. A more attractive mechanism to determine dorsal mesodermal cells could involve interactions with the ectoderm at a stage after these rearrangements have occurred. At the time when tin expression becomes restricted, the mesoderm closely contacts the epidermis and the epidermal cell fates have been specified along the

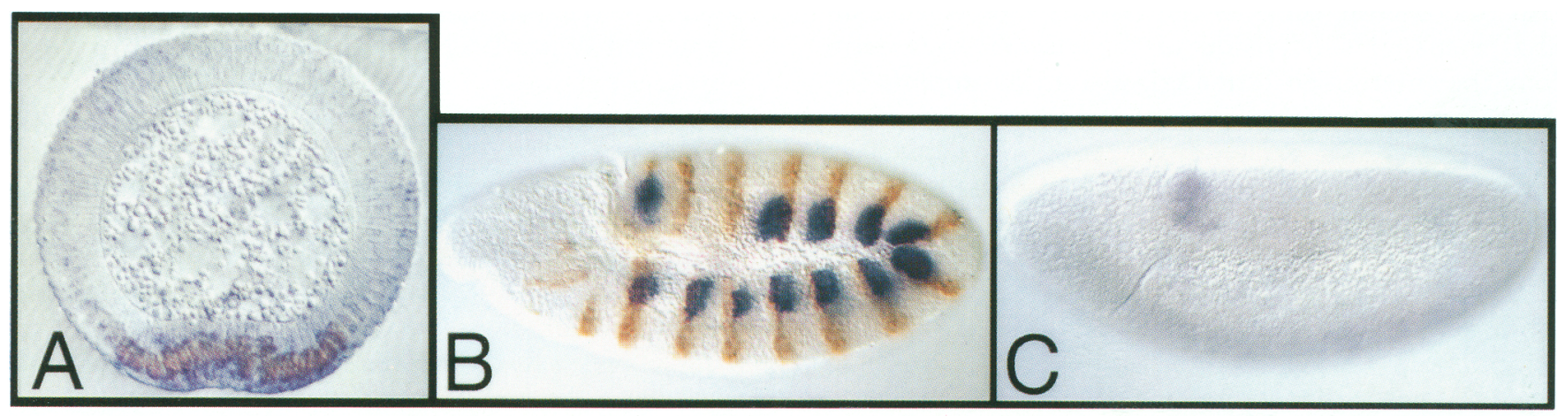

Figure 10. Early tin expression and the regulation of bap. (A) Cross section through a late blastoderm embryo, stained for tin mRNA (purple) and twist protein (brown). tin is expressed in the ventral-most cells with high nuclear contents of $t$ wist protein. (B) Wild-type embryo stained for bap mRNA (purple) and engrailed protein (brown). The anterior margins of the bap patches coincide with the anterior margins of epidermal engrailed stripes. $(C)$ bap mRNA expression in tin mutants. Except for traces [which are also seen in $\mathrm{Df}(3 \mathrm{R}) \mathrm{GC1} 4$ embryos], bap is not expressed in the dorsal mesoderm of the prospective midgut. 
dorsoventral axis. Therefore, it is conceivable that signals from epidermal regions lead to the repression of $t$ in in ventral mesoderm or to the specific maintenance of its expression in dorsal cells. This possibility can be tested by analyzing tin expression in embryos in which the fate map of epidermal regions is altered by mutations in genes of the zygotic dorsoventral class that do not directly affect the prospective mesoderm region.

Following the dorsal restriction of tin expression, this gene initiates other regulatory events leading to visceral mesoderm and heart differentiation. One candidate for a tin target gene is bap, because bap mRNA appears in the dorsal mesoderm shortly after the restriction of tin to these cells, and bap expression is dramatically reduced in tin mutants. The virtual absence of bap expression in the early mesoderm could be the result of the requirement of an activator, in addition to tin, which is perhaps only expressed after stage 9 in the mesoderm. Whereas tin is expressed in all cells of the dorsal mesoderm, bap expression is restricted to metameric repeats. The observation that the bap patches are in perfect register with the parasegments of the epidermis strongly argues for a direct or indirect role of epidermal segmentation genes in the spatial regulation of bap expression. This has been confirmed by the analysis of altered bap expression in embryos mutant for pair-rule and segment polarity genes (N. Azpiazu and M. Frasch, unpubl.). Thus, we suggest that the expression pattern of bap is a result of the combinatorial activities of $t$ in, which is present in all cells of the dorsal mesoderm, and activities that depend on segmentation genes, which restrict bap expression to segmental clusters of cells.

\section{Visceral mesoderm formation and the functions of bap}

The observation that the visceral mesoderm is derived from metamerically repeated primordia of the early mesoderm was rather unexpected because, at later stages, the visceral mesoderm forms a continuous band of cells with no overt morphological signs of segmentation. However, in more primitive insects the early visceral mesoderm is clearly segmented, and the expression patterns of homeotic genes in the visceral mesoderm indicated a spatial subdivision of the visceral mesoderm along the anterior/posterior axis also in Drosophila (Johannsen and Butt 1941; Tremml and Bienz 1989a; Reuter and Scott 1990; Reuter et al. 1990). The expression domains of most homeotic genes in this tissue are arranged in parasegmental units, and bap may well play a role in regulating their expression in these registers. $\mathrm{Al}$ ternatively, the homeotic genes could be activated in parallel to bap in these parasegmental units, as discussed above for bap (see also Tremml and Bienz 1989b). It has been shown that the visceral mesoderm, through the activities of the homeotic genes, plays a decisive role in the formation of the constrictions that arise at defined positions along the anterior/posterior axis of the midgut (Reuter and Scott 1990). Our observations suggest that this spatial organization of midgut morphogenesis may ulti- mately be a result of the metameric origin of the visceral mesoderm primordia.

Only a portion of the cells that express bap segregate to form visceral mesoderm. A main function of bap could be to define groups of cells that are competent to develop into visceral mesoderm. The cells that eventually segregate as visceral mesodermal cells could be determined as a result of communication events among the cells within each group. Similar mechanisms have been proposed for the segregation of neuroblasts and muscle founder cells from preclusters /Ghysen and DamblyChaudiere 1989; Campos-Ortega and Knust 1990; Corbin et al. 1991/. However, it is equally possible that signals from adjacent cells are required, in combination with $b a p$, to specify the ventral cells of the bap patches to become visceral mesoderm. In either of these models, bap would not necessarily be required for the differentiation of those cells in the clusters that do not form visceral mesoderm, which presumably give rise to dorsal body wall muscles. The absence of a body wall muscle phenotype in bap mutant embryos is consistent with this view. On the other hand, one might expect that lack of bap function results in the total absence of visceral mesoderm and perhaps a complete transformation of the cells normally allocated to this tissue into other mesodermal cell types. The fact that we observe residual formation of visceral mesoderm in segmental clusters and only partial transformation into somatic mesoderm may indicate that $b a p^{208}$ is not a null allele. Perhaps, the reduced function of the mutant bap protein is sufficient for the formation of some visceral mesoderm cells in the regions where bap expression persists longest and at high levels (Fig. 4G,H). Correspondingly, a phenotype similar to that of $b a p^{208}$ is seen in mutants for the weak $t i^{305}$ allele that activates bap expression only at low levels.

It seems likely that the activity of bap results in the activation of genes whose expression is restricted to the cells forming the visceral mesoderm and that regulate the differentiation of this tissue. So far, genes of this type have not been identified (see Barad et al. 1991). At the same time, bap may be directly responsible for turning on differentiation genes such as $\beta 3$-tubulin or the genes encoding the cell adhesion molecules fasciclin III and connectin (Fig. 4I; Leiss et al. 1988; Snow et al. 1989; Gould and White 1992; Nose et al. 1992).

\section{The functions of tin}

The phenotype of tin mutant embryos shows that tin functions predominantly in the dorsal mesoderm to determine the formation of visceral mesoderm, the heart, and dorsal body wall muscles. We propose that tin may fulfill these functions by providing the dorsal mesodermal cells with the competence to respond to additional cues that are spatially more restricted. Thus, cues that depend on the activities of segmentation genes appear to act in combination with tin to allow metameric bap expression and ultimately the formation of visceral mesoderm, as discussed above. Different inputs may similarly act in combination with tin to allow the formation of 
heart precursor cells in the dorsal-most part of the tin domain. As in the case of visceral mesoderm formation, this combination of activities may serve to determine preclusters of cells from which the actual heart precursors finally segregate. The involvement of neurogenic genes in this process suggests that this segregation is a result of cell-cell communication events (Hartenstein et al. 1992). The continued expression of tin in the heart cells may indicate that tin is further required for the proper differentiation of these cells. A combination of $t$ in activity with yet other inputs may be required to form particular body wall muscles in the somatic mesoderm. In tin mutant embryos, the dorsal body wall muscles, which are presumably derived from cells of the dorsal tin domain, are disrupted most strongly. Because specific muscle defects are observed more ventrally as well, it appears that tin function is also required for muscle formation during its early phase of expression in the whole mesoderm. In the absence of tin function, the precursor cells for particular body wall muscles apparently fail to become specified; and, as a consequence, the muscles they would normally form are missing in late stage embryos. This observation supports the idea that these precursors act as founder cells, which are essential to initiate the formation of individual body wall muscles, similar to the muscle pioneer cells in the grasshopper embryo (Bate 1990; Dohrmann et al. 1990; Ball et al. 1985).

\section{Indirect consequences of disrupted tin and bap functions}

We assume that in tin mutant embryos, there are transformations of cell fates similar to the ones observed in bap mutants. Thus, the cells normally destined to form visceral mesoderm and heart may become components of the multinucleate muscle fibers of the body wall musculature. Whereas in wild type the cells segregating as visceral mesoderm and heart precursors are unable to fuse with somatic muscle founder cells, in the mutants these cells fail to segregate and may be available for fusion into somatic muscle syncitia. This is in agreement with our observation that in tin mutants, the dorsolaterally located muscle 18 is often seen to contain many more nuclei than in wild type when stained for the S59 homeo domain protein (results not shown). Furthermore, the dorsal-most body wall muscles appear enlarged in $t_{i n}{ }^{-}$. In $b a p^{208}$ mutants, such enlargements are not expected to be obvious because transformations occur to a lesser extent (Fig. 6D).

The tin and bap mutants allowed us to demonstrate that the visceral mesoderm plays a role in the migration of the endoderm. The band of the visceral mesoderm appears to serve as a substrate to promote this migration. Such an interaction can ensure the intimate association of the mesodermal and endodermal layers, which is crucial for the subsequent midgut development. There is evidence that the visceral mesoderm is instrumental in the formation of the constrictions that occur in the final phases of midgut morphogenesis (Reuter and Scott 1990).
The absence of midgut constrictions in both tin and bap mutants is in line with this view. The stronger gut phenotype in tin mutants can be explained by the complete absence of midgut visceral mesoderm and by the additional failure of endoderm migration.

\section{Progressive regionalization of the mesoderm}

In summary, it appears that the regional subdivision of the mesoderm is determined through a hierarchy of gene interactions. twist is perhaps directly activating tin, and tin, in turn, is required to activate bap. An important aspect of this cascade is the presence of additional inputs at each step, which restrict the expression of each downstream gene to progressively smaller domains. Thus, tin becomes restricted to the cells of the dorsal mesoderm, and bap to segmental clusters within this region from which the cells of the visceral mesoderm segregate. These additional cues could be provided by other transcription factors expressed in overlapping domains, they could be a result of cell-cell interactions among mesodermal cells, or they may depend on inductive signals received from the epidermis. For a more complete understanding of mesoderm differentiation, it will be crucial to obtain insights into the nature of these inputs.

\section{Materials and methods \\ cDNA and genomic clones}

The genomic clones were isolated from $\lambda E M B L 4$ libraries kindly provided by $M$. Noll (University of Zürich, Switzerland) and by S. Cohen (Baylor College of Medicine, Houston, TX). cDNAs were isolated from an $8-$ to 12 -hr embryonic plasmid library (Brown and Kafatos 1988). The sequence of the bap cDNA was determined by double-stranded sequencing of both strands in the DNA core facilities of the Brookdale Center, using the TaqDyeDeoxy Terminator Cycle sequencing kit and an automated 373A DNA Sequencer (Applied Biosystems). The approximate limits of the tin and bap transcription units and the directions of transcription were determined by Southern analysis with restriction digests of the genomic clones using labeled fragments from the $5^{\prime}$ ends, the middle regions, and the $3^{\prime}$ ends of the longest cDNAs. Genomic fragments at the $5^{\prime}$ ends were sequenced to determine the sites corresponding to the $5^{\prime}$ ends of the cDNAs.

\section{Northern analysis}

Northern analysis was done as described in Dohrmann et al. (1990). For size determination, an RNA ladder (BRL) was hybridized with $\lambda$ phage DNA.

\section{In situ hybridization and antibody staining}

Transcripts were detected by in situ hybridization with digoxigenin-labeled cDNA inserts following a modification of the protocol of Tautz and Pfeifle (1989). Antibody stainings were done as described in Dohrmann et al. (1990) and in Kellermann et al. (1990). Antibodies were generously provided by C. Doe (University of Illinois, Urbana) (monoclonal engrailed antibody), C. Goodman and R. Reuter (Max Planck Institute, Tübingen, Germany) (monoclonal fasciclin III antibody), and Dan 
Kiehart (Harvard University, Cambridge, MA) (muscle myosin serum). $\beta$-Gal antibody (mouse) was purchased from Sigma and affinity purified. Phenotypes were analyzed with $\operatorname{tin}^{346}$ or $b a p^{208}$ in trans to deficiencies, and mutant embryos were identified using $\beta$-gal expressing balancer chromosomes or, in case of $t$ in, with $e v e$ antibodies to visualize heart cells. For double stainings with antibody and in situ hybridization probes, the procedures described above were modified according to a protocol from A. Manoukian and H. Krause (pers. comm.). Briefly, after fixation, the embryos were washed three times $20 \mathrm{~min}$ for each with PBTH blocking buffer (filtered; PBS, $0.1 \%$ Tween 80 , $50 \mu \mathrm{g} / \mathrm{ml}$ of heparin, $250 \mu \mathrm{g} / \mathrm{ml}$ of tRNA). The incubations with antibodies and ABC complex (Vectastain) were done as usual, but the solutions contained 1 unit of RNasin per $50 \mu \mathrm{l}$ of volume, and the washes were with PBTH. After the horseradish peroxidase reaction, the embryos were fixed again, treated with proteinase $\mathrm{K}$, postfixed, and hybridized as described above. Araldite sections of embryos were done as described by Leptin and Grunewald (1990). The embryos were photographed on a Zeiss Axiophot with Nomarski optics and Kodak technical pan, Ektachrome ET160, or Ektachrome 100 Plus films. Color slides were processed with Adobe Photoshop Macintosh version 2 (Adobe Systems, Inc.) and a Kodak XL7700 prir.ter.

\section{EMS mutagenesis}

Wild-type males with a marked third chromosome (rutipa $=r u$ th st ri roe $p^{p} e^{s} c a$ ) were mutagenized with EMS (Lewis and Bacher 1968) and crossed with TM1/TM3 females (Lindsley and Zimm 1992). Single F1 flies with the mutagenized chromosome rutipa/TM1 were crossed with flies of the genotype $D f(3 R) e^{D 7 /}$ TM1 (Scalenghe and Ritossa 1977). The F2 generation was screened for lethality of rutipa/Df(3R)e $e^{D 7}$ (absence of ebony flies). Flies with rutipa carrying a lethal mutation over TM1 were crossed among one another to establish a stock. Of the chromosomes screened, 1148 were mutagenized with $55 \mathrm{~mm}$ EMS, 4185 with $35 \mathrm{~mm}$ EMS, and 5232 with $30 \mathrm{~mm}$ EMS. The frequency of lethals in trans to the deficiency was $1.8 \%$ with 55 $\mathrm{mM}, 1.6 \%$ with $35 \mathrm{~mm}$, and $1.5 \%$ with $30 \mathrm{mM}$ EMS, and a total of 85 lethal mutations could be propagated. tin is allelic with the lethal mutation EC4O (Mohler and Pardue 1984), which we now call tin ${ }^{E C 40}$. bap was named after the shape of the gut in late stage embryos and tin after a heart phenotype described by Baum (1900).

\section{P-element mutagenesis}

$\mathrm{P}-\mathrm{lac} W$ transposable elements were mobilized from the $\mathrm{X}$ chromosome (Bier et al. 1989). Red-eyed males with $w^{1118}$ on the $\mathrm{X}$ chromosomes and P-lacW on an autosome were crossed in batches of 50 , with $150 \mathrm{w}^{1118}$ females per batch. For plasmid rescue of genomic fragments flanking the insertion sites, DNA prepared from the egg lays was cut with EcoRI, ligated, and transformed into bacteria with a Bio-Rad electroporation apparatus. Miniprep DNA was prepared from the combined bacterial colonies of each batch and tested on dot blots for hybridization with genomic probes from the tin and bap region. From the positive batch, crosses with five males and ultimately with individual males were established and tested with the same procedure. The insertion obtained this way, $\mathrm{P}\left(\mathrm{w}^{+}\right) 142$, was on a $T M 3 S b, \Delta 2-3$ chromosome, and the phenotype was analyzed in trans to $D f(3 R) e^{D 7}$. The screen was a collaboration with the Hafen and Noll laboratories (Zürich), and a detailed description is in preparation (N. Walter, M. Jenni, and E. Hafen).

To generate imprecise excisions, $\mathrm{P}\left(\mathrm{w}^{+}\right) 142$ was mobilized with the endogeneous $\Delta 2-3$ transposase (Robertson et al. 1988).
Single white-eyed flies with the genotype $+/ T M 3 S b(\Delta \mathrm{P})$ were crossed with $D f(3 R) e^{D 7} / T M 6 T b$. The next generation was screened for lethals of the genotype $D f(3 R) e^{D 7} / T M 3 S b(\Delta \mathrm{P})$. Of 500 excision events, 50 produced lethality. Seven of these mutations did not complement with tin, two of them were also semilethal over bap, and the rest failed to complement mutations in an uncharacterized gene upstream of tin. $\Delta 15$ and $\Delta 32$ (Fig. 1) also do not fully complement the latter mutations.

\section{P-mediated rescue experiments}

Genomic fragments (Fig. 1B) were cloned into the transformation vectors pCaSpeR2 (tin) or pCaSpeR3 (bap) (Pirrotta 1988). $\mathrm{P}$-insertions on the second or $\mathrm{X}$ chromosome were crossed into the mutant background of tin or bap $/ D f(3 R) e^{D 7}$. Insertions on the third chromosome were first recombined onto this deficiency chromosome, which was then tested in trans to the tin or bap mutant chromosomes. In all cases, we tested for survival of ebony flies. Seven of eight independent insertions with the tin genomic region rescued the lethality of the weak allele $t^{305}$ and two of four tested rescued strong mutation $\operatorname{tin}^{346}$. With the insertion Re28-102, which gave the strongest rescue, $40 \%$ of the expected flies mutant for the weak allele and $48 \%$ of the expected flies mutant for the strong allele survived to adulthood. Of 12 independent insertions with the bap genomic region, 7 rescued the lethality of $b a p^{208}$. The strongest rescue with a $60 \%$ survival rate was obtained in line $\operatorname{Re} 3-89$.

\section{lacZ reporter constructs}

A 4.5 -kb BamHI fragment $(+6$ to $+10.5 \mathrm{~kb}$; Fig. $1 \mathrm{~B})$ was cloned into the transformation vector pCaSpeRhs43ßgal (Thummel et al. 1988) in the native orientation. Six transformed lines with identical $\beta$-gal-expression in the visceral mesoderm were obtained. An insertion on the second chromosome, baplac $4.5 \# 23$, was crossed into the mutant backgrounds of $b^{2} p^{208} / D f(3 R) e^{D 7}$ and $\operatorname{tin}^{346} / D f(3 R) e^{D 7}$.

\section{Fly stocks}

The enhancer trap stocks Al76.1M2 and A490.2M3 (Bellen et al. 1989) were obtained through the Bloomington stock collection and through R. Reuter. E2-3-9 was produced by Bier et al. (1989) and analyzed further by Hartenstein et al. (1992). The 93E deficiency stocks were obtained from J. Mohler (Barnard College, NY), and M.L. Pardue (MIT, Cambridge, MA), and the rutipa stock was from the Tübingen stock collection.

\section{Acknowledgments}

We thank C. Nüsslein-Volhard and S. Roth for teaching us how to do genetic screens, E. Hafen and N. Walter for organizing the $P$-screen and for their hospitality, P. Küssel for participating in this screen, I. Koch and Z. Yin for technical assistance, R. Reuter for discussions and communication of unpublished results, D. Kiehart, and A. Martinez-Arias, and C. Doe for antibodies, and J. Mohler, M.L. Pardue, V. Hartenstein, and H. Bellen for fly stocks. We gratefully appreciate the helpful comments on the manuscript by C. Rushlow, L. Pick, and D. Stein. Parts of this work were supported by a grant from the Deutsche Forschungsgemeinschaft and a European Molecular Biology Organization (EMBO) short-term fellowship to M.F., and N.A. was supported by a fellowship from the Government of Euskadi (Basque country).

The publication costs of this article were defrayed in part by payment of page charges. This article must therefore be hereby 
marked "advertisement" in accordance with 18 USC section 1734 solely to indicate this fact.

\section{Note added in proof}

The bagpipe cDNA sequence has been submitted to the GenBank data library under accession number T17133.

\section{References}

Ball, E.E., R.K. Ho, and C.S. Goodman. 1985. Development of neuromuscular specificity in the grasshopper embryo: Guidance of motoneuron growth cones by muscle pioneers. $I$. Neurosci. 5: 1808-1819.

Barad, M., A. Erlebacher, and W. McGinnis. 1991. Despite expression in embryonic visceral mesoderm, H2.0 is not essential for Drosophila visceral muscle morphogenesis. Dev. Genet. 12: 206-211.

Bate, M. 1990. The embryonic development of larval muscles in Drosophila. Development 110: 791-804.

Baum, L.F. 1900. The wizard of Oz. George M. Hill, Chicago, IL.

Beer, J., G.M. Technau, and J.A. Campos-Ortega. 1987. Lineage analysis of transplanted individual cells in embryos of Drosophila melanogaster. Commitment and proliferative capabilities of mesodermal cells. Wilhelm Roux's Arch. 196: $220-230$.

Bellen, H.J., C.J. O'Kane, C. Wilson, U. Grossniklaus, R.K. Pearson, and W.J. Gehring. 1989. P-element-mediated enhancer detection: A versatile method to study development in Drosophila. Genes \& Dev. 3: 1288-1300.

Bier, E., H. Vaessin, S. Shepherd, K. Lee, K. McCall, S. Barbel, L. Ackerman, R. Carretto, T. Uemura, E. Grell, L.Y. Jan, and Y.N. Jan. 1989. Searching for pattern and mutation in the Drosophila genome with a P-lacZ vector. Genes \& Dev. 3: 1273-1287.

Bodmer, R., L.Y. Jan, and Y.N. Jan. 1990. A new homeoboxcontaining gene, msh-2, is transiently expressed early during mesoderm formation of Drosophila. Development 110: 661669.

Boulay, J.L., C. Dennefeld, and A. Alberga. 1987. The Drosophila developmental gene snail encodes a protein with nucleic acid binding fingers. Nature 330: 395-398.

Brown, N.H. and F.C. Kafatos. 1988. Functional cDNA libraries from Drosophila embryos. J. Mol. Biol. 203: 425-437.

Campos-Ortega, J.A. and V. Hartenstein. 1985. The embryonic development of Drosophila melanogaster. Springer Verlag, Berlin, Germany.

Campos-Ortega, J.A. and E. Knust. 1990. Genetic mechanisms in early neurogenesis of Drosophila melanogaster. Annu. Rev. Genet. 24: 387-407.

Cavener, D.R. 1987. Comparison of the consensus sequence flanking translational start sites in Drosophila and vertebrates. Nucleic Acids Res. 15: 1353-1361.

Corbin, V., A.M. Michelson, S.M. Abmayr, V. Neel, E. Alcamo, T. Maniatis, and M.W. Young. 1991. A role for the Drosophila neurogenic genes in mesoderm differentiation. Cell 67: 311-323.

Crossley, A.C. 1978. The morphology and development of the Drosophila muscular system. In Genetics and biology of Drosophila (ed. M. Ashburner and T.R.F. Wright), Vol. 2b, pp. 499-560. Academic Press, London, U.K.

Dohrmann, C., N. Azpiazu, and M. Frasch. 1990. A new Drosophila homeo box gene is expressed in mesodermal precursor cells of distinct muscles during embryogenesis. Genes \& Dev. 4: 2098-2111.
Frasch, M., T. Hoey, C. Rushlow, H.J. Doyle, and M. Levine. 1987. Characterization and localization of the even-skipped protein of Drosophila. EMBO I. 6: 749-759.

Gerhart, J.C., R. Steward, and T. Doniach. 1991. Organizing the Xenopus organizer. In Gastrulation: Movements, patterns and molecules (ed. R. Keller, W.J. Clark, and F. Griffin), pp. 55-77. Plenum Press, New York.

Ghysen, A. and C. Dambly-Chaudiere. 1989. Genesis of the Drosophila peripheral nervous system. Trends Genet. 5: 251-255.

Gould, A. and R.A.H. White. 1992. Connectin, a target of homeotic gene control in Drosophila. Development 116: 11631174.

Guazzi, S., M. Price, M. DeFelice, G. Damante, M.-G. Mattei, and R. DiLauro. 1990. Thyroid nuclear factor 1 (TTF-1) contains a homeo domain and displays a novel DNA binding specificity. EMBO I. 9: 3631-3639.

Hartenstein, A.Y., A. Rugendorff, U. Tepass, and V. Hartenstein. 1992. The function of the neurogenic genes during epithelial development in the Drosophila embryo. Development 116: 1203-1220.

Hartenstein, V. and Y.N. Jan. 1992. Studying Drosophila embryogenesis with P-lacZ enhancer trap lines. Wilhelm Roux's Arch. Dev. Biol. 201: 194-220.

Ip, T.Y., R.E. Park, D. Kosman, K. Yazdanbakhsh, and M. Levine. 1992. dorsal-twist interactions establish snail expression in the presumptive mesoderm of the Drosophila embryo. Genes \& Dev. 6: 1518-1530.

Jiang, J., D. Kosman, Y.T. Ip, and M. Levine. 1991. The dorsal morphogen gradient regulates the mesoderm determinant twist in early Drosophila embryos. Genes \& Dev. 5: 18811891.

Johannsen, O.A. and F.H. Butt. 1984. Embryology of insects and myriapods. McGraw-Hill, New York/London.

Kellermann, K.A., D.M. Mattson, and I. Duncan. 1990. Mutations affecting the stability of the fushi tarazu protein of Drosophila. Genes \& Dev. 4: 1936-1950.

Kim, Y. and M. Nirenberg. 1989. Drosophila NK-homeobox genes. Proc. Natl. Acad. Sci. 86: 7716-7720.

Kimelman, D., J.L. Christian, and R.T. Moon. 1992. Synergistic principles of development: Overlapping patterning systems in Xenopus mesoderm induction. Development 116: 1-9.

Kosman, D., Y.T. Ip, M. Levine, and K. Arora. 1991. Establishment of the mesoderm-neuroectoderm boundary in the Drosophila embryo. Science 252: 118-122.

Leiss, D., U. Hinz, A. Gasch, R. Mertz, and R. Renkawitz-Pohl. 1988. $\beta 3$ tubulin expression characterizes the differentiating mesodermal germ layer during Drosophila embryogenesis. Development 104: 525-531.

Leptin, M. 1991. twist and snail as positive and negative regulators during Drosophila mesoderm formation. Genes \& Dev. 5: 1568-1576.

Leptin, M. and B. Grunewald. 1990. Cell shape changes during gastrulation in Drosophila. Development 110: 73-84.

Lewis, E.P. and F. Bacher. 1968. Method of feeding ethyl methane sulfonate (EMS) to Drosophila males. Drosophila Inf. Serv. 43: 193.

Lindsley, D.L. and G.G. Zimm. 1992. The genome of Drosophila melanogaster Academic Press, San Diego, CA.

Mohler, J. and M.L. Pardue. 1984. Mutational analysis of the region surrounding the 93D heat shock locus of Drosophila melanogaster. Genetics 106: 249-265.

Nose, A., V.B. Mahajan, and C.S. Goodman. 1992. Connectin: A homophilic cell adhesion molecule expressed on a subset of muscles and the motoneurons that innervate them in Drosophila. Cell 70: 553-567. 
Pirrotta, V. 1988. Vectors for P-mediated transformation in Drosophila. In Vectors, a survey of molecular cloning vectors and their uses (ed. R.L. Rodriquez and D.T. Denhardt) pp. 437-456. Butterworth, Boston, MA.

Poulson, D.F. 1950. Histogenesis, organogenesis, and differentiation in the embryo of Drosophila melanogaster. In The biology of Drosophila. Wiley, New York.

Price, M., D. Lazzaro, T. Pohl, M.-G. Mattei, U. Rüther, J.-C. Olivo, D. Duboule, and R. DiLauro. 1992. Regional expression of the homeo box gene Nkx-2.2 in the developing mammalian forebrain. Neuron 8: 241-255.

Reuter, R. and M.P. Scott. 1990. Expression and function of the homoeotic genes Antennapedia and Sex combs reduced in the embryonic midgut of Drosophila. Development 109: 289-303.

Reuter, R., G.E.F. Panganiban, F.M. Hoffmann, and M.P. Scott. 1990. Homeotic genes regulate the spatial expression of putative growth factors in the visceral mesoderm of Drosophila embryos. Development 110: 1031-1040.

Robertson, H.N., C.R. Preston, R.W. Phillis, D.M. JohnsonSchlitz, W.K. Benz, and W. Engels. 1988. A stable genomic source of P-element transposase in Drosophila melanogaster. Genetics 118: 461-470.

Roth, S., D. Stein, and C. Nüsslein-Volhard. 1989. A gradient of nuclear localization of the dorsal protein determines dorsoventral pattern in the Drosophila embryo. Cell 59: 11891202.

Ruiz i Altaba, A., and D.A. Melton. 1990. Axial patterning and the establishment of polarity in the frog embryo. Trends Genet. 6: 57-64.

Rushlow, C.A., K. Han, J.L. Manley, and M. Levine. 1989. The graded distribution of the dorsal morphogen is initiated by selective nuclear transport in Drosophila. Cell 59: 11651177.

Scalenghe, F. and F. Ritossa. 1977. The puff inducible in region 93D is responsible for the major "heat shock" polypeptide in Drosophila melanogaster. Chromosoma 63: 317-362.

Simpson, P. 1983. Maternal-zygotic gene interactions during formation of the dorsoventral pattern in Drosophila embryos. Genetics 105: 615-632.

Smith, J.C. 1989. Mesoderm induction and mesoderm-inducing factors in early amphibian development. Development 105: 665-677.

Snow, P.M., A.J. Bieber, and C.S. Goodman. 1989. Fasciclin III: A novel homophilic adhesion molecule in Drosophila. Cell 59: 313-323 .

Stadler, H.S., B.J. Padanilam, K. Buetow, J.C. Murray, and M. Solursh. 1992. Identification and genetic mapping of a homeobox gene to the 4 pl6.1 region of human chromosome 4 . Proc. Natl. Acad. Sci. 89: 11579-11583.

Steward, R. 1989. Relocalization of the dorsal protein from the cytoplasm to the nucleus correlates with its function. Cell 59: 1179-1188 .

Tautz, D. and C. Pfeifle. 1989. A nonradioactive in situ hybridization method for the localization of specific RNAs in Drosophila embryos reveals translational control of the segmentation gene hunchback. Chromosoma 98: 81-85.

Thisse, B., C. Stoetzel, C. Gorostiza-Thisse, and F. PerrinSchmitt. 1988. Sequence of the twist gene and nuclear localization of its protein in endomesodermal cells of early Drosophila embryos. EMBO f. 7: 2175-2183.

Thisse, C., F. Perrin-Schmitt, C. Stoetzel, and B. Thisse. 1991. Sequence-specific transactivation of the Drosophila twist gene by the dorsal gene product. Cell 65: 1191-1201.

Thummel, C.S., A.M. Boulet, and H.D. Lipshitz. 1988. Vectors for Drosophila P-element-mediated transformation and tis- sue culture transfection. Gene 74: 445-450.

Tremml, G. and M. Bienz. 1989a. Homeotic gene expression in the visceral mesoderm of Drosophila embryos. EMBO $J$. 8: $2677-2685$

1989b. An essential role of even-skipped for homeotic gene expression in the Drosophila visceral mesoderm. $E M B O$ I. 8: 2687-2693.

von Dassow, G., J.E. Schmidt, and D. Kimelman. 1993. Induction of the Xenopus organizer: Expression and regulation of Xnot, a novel FGF an activin-regulated homeo box gene. Genes \& Dev. 7: 355-366. 


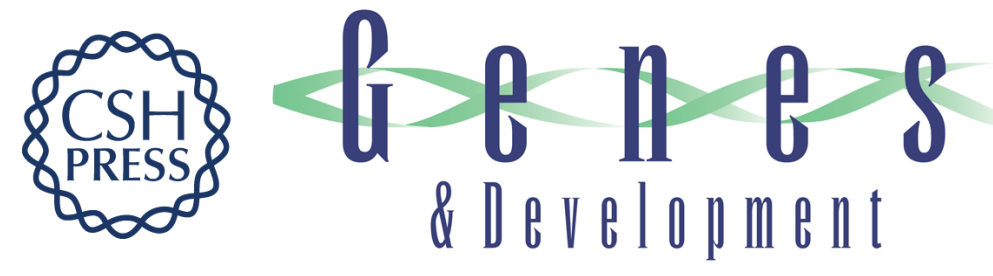

\section{tinman and bagpipe: two homeo box genes that determine cell fates in the dorsal mesoderm of Drosophila.}

N Azpiazu and M Frasch

Genes Dev. 1993, 7:

Access the most recent version at doi:10.1101/gad.7.7b.1325

References This article cites 51 articles, 24 of which can be accessed free at:

http://genesdev.cshlp.org/content/7/7b/1325.full.html\#ref-list-1

License

Email Alerting

Receive free email alerts when new articles cite this article - sign up in the box at the

Service top right corner of the article or click here.

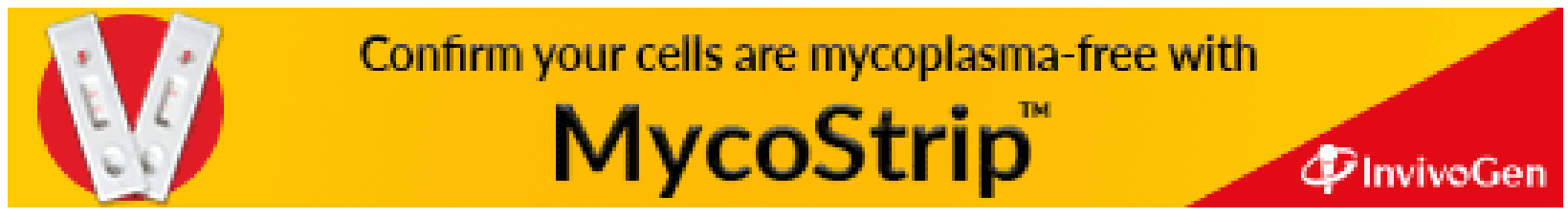

